Bryn Mawr College

Scholarship, Research, and Creative Work at Bryn Mawr College

Graduate School of Social Work and Social

Graduate School of Social Work and Social

Research Faculty Research and Scholarship

Research

2016

\title{
A Measure of Comprehensive Airman Fitness: Construct Validation and Invariance Across Air Force Service Components
}

Gary L. Bowen

Todd M. Jensen

James A. Martin

Bryn Mawr College, jmartin@brynmawr.edu

Let us know how access to this document benefits you.

Follow this and additional works at: http://repository.brynmawr.edu/gsswsr_pubs

Part of the Social Work Commons

\section{Custom Citation}

Bowen, Gary L., Todd M. Jensen, and James A. Martin. "A Measure of Comprehensive Airman Fitness: Construct Validation and Invariance Across Air Force Service Components." Military Behavioral Health 4, no. 2 (2016): 149-158. doi: 10.1080/ 21635781.2015 .1133345

This paper is posted at Scholarship, Research, and Creative Work at Bryn Mawr College. http://repository.brynmawr.edu/gsswsr_pubs/64

For more information, please contact repository@brynmawr.edu. 
A Measure of Comprehensive Airman Fitness:

Construct Validation and Invariance Across Air Force Service Components

Gary L. Bowen and Todd M. Jensen

University of North Carolina at Chapel Hill

James A. Martin

Bryn Mawr College

\section{Author Notes}

Gary L. Bowen, PhD is a Kenan Distinguished Professor in the School of Social Work at the University of North Carolina at Chapel Hill.

Todd M. Jensen, MSW is a doctoral candidate in the School of Social Work at the University of North Carolina at Chapel Hill.

James A. Martin, PhD is a retired Army Officer and a Professor of Social Work and Social Research at Bryn Mawr College.

The views and opinions contained in this article are those of the authors and should not be construed as official Department of the Air Force position, policy, or decision, unless so designated by other authorized documents. Data reported in this article were collected by Flying Bridge Technologies, Inc., Charlotte, N.C., under Task Order Number 9Q1 SFSRAB001, General Services Administration. The Office of Human Research Ethics at the University of North Carolina at Chapel Hill determined that the proposed secondary analysis of these data was exempt from human subject review.

Correspondence concerning this article should be addressed to Gary L. Bowen, School of Social Work, The University of North Carolina at Chapel Hill, 325 Pittsboro Street, Chapel Hill, NC 27599-3550. E-mail: glbowen@email.unc.edu 


\begin{abstract}
This article addresses the construct validity of an on-line assessment measure intended to reflect the biospychosocial and spiritual fitness of U.S. Air Force members - defined as Comprehensive Airman Fitness. The analysis presented examines the extent to which this measure and the associated validation model are invariant across three AF components: Active Duty personnel, members of the Air National Guard/AF Reserve, and AF civilian employees. Our results indicate that total fitness (i.e., second-order factor), its four sub-components (i.e., first-order factors), and the resiliency construct associated with role performance are invariant across service components at the configural, metric, and scalar measurement levels. Further, the strong positive association between total fitness and resiliency is statistically indistinguishable across all AF components. Limitations and implications are discussed.

Keywords: Comprehensive Airman Fitness, total force fitness, U.S. military, U.S. Air Force, Support and Resiliency Inventory, confirmatory factor analysis
\end{abstract}




\section{A Measure of Comprehensive Airman Fitness:}

\section{Construct Validation and Invariance Across Air Force Service Components}

The United States Air Force (AF) launched an AF-wide Comprehensive Airman Fitness (CAF) program on March 30, 2011 (Gonzalez, Singh, Schell, \& Weinich, 2014) and specific CAF organizational and installation program requirements were later specified in AF Instruction (AFI) 90-506 (2 April 2014). While operating within a broad health promotion framework specified by the Department of Defense (CJCSI 3405.01, 1 September 2011), the AF CAF program is focused on "a holistic approach that incorporates a capabilities-based, total life-cycle approach to managing Airmen - a performance-based force projection model that concentrates on human performance" (Tvaryanas, Brown, \& Miller, 2009, p. 35). Defining "airmen" broadly to encompass all members of the AF community (service members, their spouses and children, as well as AF civilian employees), the CAF framework is focused on four core fitness components: mental, physical, social, and spiritual. AF leaders and supervisors are instructed to "understand, promote, and support CAF," ensuring that AF members are prepared mentally, physically, socially, and spiritually to carry out their missions" (AFI 90-506, p. 3). The CAF goal is to promote and sustain "a fit, resilient, and ready force" (AFI 90-506, p. 3).

Bowen, Jensen, and Martin (in review) recently noted that the AF leadership has not established a measure for assessing CAF and its related components, although AF policy guidance (AFI 90-506) references the importance of such metrics and indicators for commanders and AF community planning groups. This is in direct contrast to developments in the U.S. Army, which has made assessment (The Global Assessment Tool) a cornerstone of its Comprehensive Soldier Fitness program (Peterson, Park, \& Castro, 2011). 
Using a sample of active-duty AF members who completed a brief on-line assessment (Support and Resiliency Inventory; SRI; Bowen \& Martin, 2011b) in conjunction with an AF Chief of Staff directed suicide prevention "stand-down" during a two-week period in January of 2012 (Department of the Air Force, 2012a), Bowen et al. (in review) conducted rigorous confirmatory factor and multiple group comparison analyses to empirically validate a 12 -item measure of the four fitness components (and an overall or total component) of Comprehensive Airman Fitness. Their results indicated that the four individual CAF latent constructs, each measured with three observed indicators, loaded onto a second-order latent construct of total CAF. Results indicated that the CAF instrument was invariant across subgroups defined by military pay grade, gender, marital status, and deployment status in the past 12 months.

Using an expanded respondent version of the same data source, the present analysis examined the construct validity of the total CAF measure using a three-item measure of resiliency derived from measuring human performance within the inherently stressful conditions of military duties and service life that exist for our Armed Forces in the post 9/11 military operational environment (Bowen \& Martin, 2013). According to DeVellis (2012), construct validity "is directly concerned with the theoretical relation of a variable to other variables" (p. 64). Thus, to provide evidence of construct validity, scores of a measure should influence other theoretically relevant constructs in expected and predictable ways. Further, we tested the measurement and structural invariance of the model for respondents serving on active duty, for members of the Air National Guard and AF Reserve, as well as for AF civilian employees.

\section{Hypothesized Model}

Figure 1 illustrates the hypothesized model that is tested in this investigation. As confirmed in the earlier analysis (Bowen et al., in review), the model shows a total of 12 
observed variables associated with four first-order latent fitness factors (mental, physical, social, and spiritual). Table 1 includes nominal definitions of these components, as defined in AFI 90506. The model also shows a second-order factor structure in which the four first-order latent fitness factors load onto a higher-order latent factor, total fitness.

<Insert Figure 1 about here>

The construct validity of the fitness measure is examined with the addition of a performance-based resiliency measure, which is defined as a latent factor with three observed variables. Resiliency is conceptualized as an outcome, which reflects the successful performance of important personal and military life roles (see Bowen \& Martin, 2011a who make an important distinction between resilience as a process and resiliency as an outcome of the resilience process). In a recent review of resilience in military families, Wright, Riviere, Merrill, and Cabrera (2013) note that the majority of studies assess proxies for resilience, "such as adaptation, satisfaction, and other 'competent functioning' indicators," rather than resilience per se (pp. 175-176). In Figure 1, total fitness is expected to have a direct and positive influence on performance-based resiliency. The expectation is consistent with the resiliency model of role performance (Bowen \& Martin, 2011a) and it directly addresses the AF objective of a program model that concentrates on human performance.

<Insert Table 1 about here>

The measurement and structural components of the model in Figure 1 are expected to be invariant across the three respondent groups: individuals who are currently serving on active duty, members of the Air National Guard and AF Reserve, and AF civilian employees. Such invariance would suggest that the model reliably captures the same constructs and construct 
associations across respondent groups, and that any measurement or structural differences between groups are statistically negligible.

\section{Methods}

\section{Source of Data}

In January 2012 the AF Chief of Staff, General Norton A. Schwartz (2008-2012), and the Chief Master Sergeant of the Air Force, James A. Roy (2009-2013), directed a one-day stand down for all Air Force units worldwide to focus on member, unit, and community resiliency (Department of the Air Force, 2012a). As noted at the time, the stand down was in direct response to their concerns as senior leaders regarding an observed uptick in the AF suicide rate.

Associated with this mandatory event, individuals and units (including military members and AF civilian employees) were offered the opportunity to complete the web-based Support and Resiliency Inventory (SRI) as a means of facilitating stand-down discussions (Department of the Air Force, 2012b). During a two-week timeframe (12 January 2012 to 26 January 2012), 11,885 AF service members and civilian employees voluntarily completed the SRI in support of this command directive. All SRI responses were anonymous.

Although information from the SRI was intended to inform the design, delivery, and evaluation of programs and services that promote the fitness and resilience of AF service members and civilian employees at unit, installation, and/or Major Command levels, this administration had a specific purpose - to allow service members and civilian employees to examine their own fitness and resilience profile as part of the stand-down conversation. The SRI was well suited for this purpose, as respondents were able to download and review a graphical summary of their responses at the end of the 15-minute on-line assessment, including their individual fitness profile. A web-based worksheet provided respondents with an opportunity to 
develop an individual plan of action for increasing their own success in adapting to life challenges and meeting military life and duty responsibilities.

\section{Sample Profile}

The current study focuses on the 10,846 individuals comprising three sub-groups of respondents from the larger sample. They include individuals who were currently serving on active duty $(N=8,671)$, members of the Air National Guard and AF Reserve $(N=417)$, and AF civilian employees $(N=1,758)$. Individuals who were currently deployed were omitted from the sample $(N=184)$ because their experiences and responses may fundamentally differ from nondeployed members, based on the nature of the deployment experience. Unfortunately, the current data did not address the nature of deployment or current stress exposures. While it was not possible to determine the unit and location of respondents who used a "portal-based" selfadministration of the SRI $(\mathrm{N}=4,042)$ rather than the "unit-based" administration $(\mathrm{N}=6,804)$, respondents using the "unit-based" administration represented nearly 100 AF units across 26 installations. Table 2 includes a profile description of the full sample. The modal respondent was male $(75 \%)$, married (62\%), and a parent or stepparent (56\%). A little over one-third of respondents were under the age of $26(35 \%)$.

\section{< Insert Table 2 About Here >}

\section{Measures}

Fifteen items were used to assess the five first-order constructs in the hypothesized model: resiliency, defined in terms of three self-assessed single-item measures of current role performance (3 items: R1, R2, R3; $\alpha=.81$ ), mental fitness (3 items: MF1, MF2, MF3; $\alpha=.90$ ), physical fitness (3 items: PF1 PF2, PF3; $\alpha=.86$ ), social fitness (3 items: SCF1, SCF2, SCF3; $\alpha=$ 
.80 ), spiritual fitness (3 items: SPF1, SPF2, SPF3; $\alpha=.94$ ). Total fitness, the second-order factor, comprised mental, physical, social, and spiritual first-order factors.

< Insert Table 3 About Here >

Table 3 displays the items, and their descriptions, that correspond with each latent construct. Modeled after Cantril's (1965) self-anchoring ladder scale, each item was measured on the same 11-point scale from 0 (not at all) to 10 (completely). Table 2 presents descriptive statistics for all items, and Table 4 displays the associated correlation matrix. The three groups previously described were used for the conduct of measurement and structural invariance tests: AF Active Duty (heretofore referred to as "Active Duty"), Air National Guard/AF Reserve (heretofore referred to as "Guard \& Reserve"), and civilian employees (heretofore referred to as “Civilian”).

< Insert Table 4 About Here >

\section{Data Analysis}

We began with the univariate and bivariate analysis of observed indicators in Stata 13.0 (StataCorp, 2013). Because tests of multivariate normality are sensitive to sample size (Kline, 2011), we examined the skew index and kurtosis index values associated with each observed indicator (see Table 2; Kline, 2011). Across the 15 observed indicators, skew index values were less than 2.04 (average $=-1.25)$, and kurtosis index values were less than 8.66 (average $=4.56$ ). This indicated that the distributions of our measures may not be problematic (Curran, West \& Finch, 1996; Kline, 2011); however, we took precautions (discussed below) to address this assumption. We analyzed a correlation matrix for all observed indicators in order to examine inter-item associations. Our analysis then consisted of two core components: a) an assessment of the construct (i.e., predictive) validity of the $\mathrm{CAF}$ instrument by examining its influence on a 
measure of resiliency, and b) an assessment of measurement and structural invariance of the model across our sample of Active Duty, Guard \& Reserve, and Civilian AF members. Structural equation modeling (SEM) in Mplus 7.11 (Muthén \& Muthén, 2012) was used to conduct these analyses.

We used the following specific model fit criteria to evaluate the acceptability of all models: root mean square error of approximation (RMSEA) and its upper-bound 90\% confidence interval $\leq .08$ (Browne \& Cudeck, 1993), Tucker-Lewis Index (TLI) $\geq .95$, and Comparative Fit Index $(\mathrm{CFI}) \geq .95$ (Hu \& Bentler, 1999). Because our samples were large, and chi-square difference tests are generally sensitive to the size of samples, we abided by the counsel of Cheung \& Rensvold (2002) and determined that model constraints were statistically negligible if the associated change in CFI was smaller than or equal to -0.01 (i.e., $\Delta \mathrm{CFI} \leq-0.01$ ). Although our data were ordinal, items with more than 10 response options cannot be specified as ordinal in Mplus. Thus, we used a Maximum Likelihood (ML) estimator. To ensure our results were not sensitive to the distributional properties of observed indicators, we re-analyzed our final model with Maximum Likelihood estimation with robust standard errors (MLR) and assessed any notable differences. Missing data (less than $2.4 \%$ of all data analyzed) were handled with fullinformation maximum likelihood estimation (i.e., FIML).

We adapted the strategy outlined by Chen, Sousa, and West (2005) to inform the measurement invariance testing process with our second-order factor model and its influence on resiliency. In a step-wise manner, we assessed configural invariance (i.e., equivalent factor structure), first-order metric invariance (i.e., equivalent first-order factor loadings), second-order metric invariance (i.e., equivalent second-order factor loadings), and first-order scalar invariance (i.e., equivalent observed indicator intercepts) across service component groups with respect to 
the following latent constructs: mental fitness, physical fitness, social fitness, spiritual fitness, total fitness (second-order factor), and resiliency. Measurement invariance tests were conducted in the context of a measurement model (no structural paths were specified and all constructs were allowed to be correlated with one another).

If full invariance could not be established at a particular step, an assessment of partial invariance was conducted (N. Bowen \& Masa, 2015; Byrne, Shavelson, \& Muthen, 1989). Dimitrov (2010) described partial invariance as "a situation in which there is no perfect invariance for specific parameters, but neither is there evidence of their complete inequality" (p.127). Freely estimating less than $20 \%$ of parameters at a given stage of invariance-testing may be acceptable, and have negligible consequences on the continuation of subsequent invariance tests (Dimitrov, 2010). If necessary, the most problematic constraints, as informed by modification indices in Mplus, were freely estimated across groups one-by-one to uncover the most appropriate constellation of constrained and freely estimated parameters. Following measurement invariance tests, structural invariance tests were conducted to assess whether or not the structural path between total fitness and resiliency could be constrained to equality across the service component groups without worsening model it.

For the purpose of obtaining model identification and metric calibration in Mplus, firstand second-order factor means and variances/error variances were fixed to 0 and 1, respectively. Preliminary analyses indicated that the measurement model was over-identified and sufficiently powered (N. Bowen \& Guo, 2012; MacCallum, Browne, \& Sugawara, 1996). We note, however, that the structural model was just-identified (i.e., the number of known structural observations equaled the number of unknown structural parameters to be estimated). No modifications to the model were made that were not specified in the hypothesized model. 


\section{Results}

\section{Measurement Invariance Tests}

Table 5 displays results from measurement invariance tests, including model fit indices and $\triangle \mathrm{CFI}$ associated with the addition of model constraints. Results indicated that the baseline model (Model 1) fit the data well, as indicated by goodness-of-fit values above our pre-specified cutoff values: $\chi 2(50)=1094.918, \mathrm{p}<.001$, RMSEA $=.044$ [upper-bound 90\% CI: .046], TLI = .985 , and CFI $=.988$. Results also indicated that configural (Model 2), first-order metric (Model 3), and second-order metric invariance (Model 4) could be specified across Active Duty, Guard $\&$ Reserve, and Civilian components without significantly worsening model fit $(\Delta \mathrm{CFI}=-.009,-$ .005 , and .000, respectively). Full scalar invariance (Model 5; equivalent first-order intercepts), however, could not be specified without significantly worsening model fit $(\Delta \mathrm{CFI}=-.015)$. Thus, we examined the modification indices in the Mplus (Dimitrov, 2010) output and found that freely estimating PF2 (i.e., "I exercise on a regular basis") across groups would optimize gains in model fit. After analyzing the model with this parameter freely estimated, we found that this model (Model 6) did not significantly worsen model fit compared to the metric invariant model (Model 4; $\triangle \mathrm{CFI}=-.009)$. Therefore, we were able to constrain 14 out of 15 , or $93 \%$, of all observed indicator intercepts to equality across groups without worsening model fit, providing enough invariance to justify subsequent structural invariance tests (Dimitrov, 2010). Model 6 yielded acceptable fit as indicated by the following model fit indices: $\chi 2(321)=4186.046, p<$ $.001, \mathrm{RMSEA}=.058$ [upper-bound $90 \% \mathrm{CI}: .059], \mathrm{TLI}=.965$, and CFI $=.965$.

< Insert Table 5 About Here >

\section{Structural Invariance Tests}


After establishing configural, first-order metric, second-order metric, and partial firstorder scalar invariance, we analyzed the structural model (Model 7). In this model, the resiliency construct was regressed on the second-order total fitness construct. Results indicated no significant change in model fit compared to Model $6(\Delta \mathrm{CFI}=.000)$, although this likely represents the fact that the structural model was just-identified. In Model 8, we constrained the structural parameter to equality across Active Duty, Guard \& Reserve, and Civilian service components. Results indicated that this structural invariance could be specified without significantly worsening model fit $(\triangle \mathrm{CFI}=.000)$. Model 8 yielded acceptable fit as indicated by the following model fit indices: $\chi 2(323)=4187.358, \mathrm{p}<.001, \mathrm{RMSEA}=.058$ [upper-bound 90\% CI: .059], TLI $=.966$, and CFI $=.965$. All parameters in Model 8 were significant at the $\mathrm{p}<$ .001 level, and are available upon request.

\section{Final Model}

For the final model, and based on the results of measurement and structural invariance tests, we analyzed the hypothesized model with the full sample together (rather than partitioned between Active Duty, Guard \& Reserve, and Civilian respondents). Figure 2 displays the results associated with the final model. The model yielded acceptable fit as indicated by the following model fit indices: $\chi 2(85)=2328.756, \mathrm{p}<.001, \mathrm{RMSEA}=.049$ [upper-bound 90\% CI: .051], TLI $=.974$, and CFI $=.979$. Standardized first-order factor loadings ranged from .659 to .974 , and standardized second-order factor loadings ranged from .574 to .850 .

In terms of the structural parameter, results indicated that a one standard deviation increase in total fitness was associated with a .794 standard deviation increase in resiliency $(\beta=$ $.794, \mathrm{~b}=1.304, \mathrm{p}<.001)$. Results also indicated that $63 \%$ of the variation in resiliency was explained by total fitness $\left(\mathrm{R}^{2}=.63\right)$. Thus, as expected, total fitness was strongly and positively 
associated with resiliency. As mentioned previously, the final model was re-analyzed with MLR as a robustness check. The substantive results were identical to those estimated with ML (i.e., all parameters remained unchanged and significant at the $\mathrm{p}<.001$ level).

$<$ Insert Figure 2 About Here >

\section{Discussion and Implications}

The purpose of this study was to assess the construct validity of the CAF measure by examining its association with resiliency, and to examine the extent to which the instrument and validation model were invariant across three AF components: Active Duty, Guard \& Reserve, and Civilian employees. Using SEM, our results indicated that total fitness, its four subcomponents, and the resiliency construct were invariant across service components at the configural, metric, and scalar measurement levels. We also found that the strong positive association between total fitness and resiliency was statistically indistinguishable across all service components. Taken together, these findings indicate that the CAF instrument measures the same phenomena across all three AF components, and that total fitness is positively linked to resiliency, irrespective of one's component membership. This is an important senior leadership finding since it supports use of assessment data, as well as policy and program responses, both within and across AF components. Although it is beyond the focus of the current investigation, in the context of being anchored in the Department of Defense's Force Fitness model, the CAF is also easily adaptable across service components.

These findings provide strong validation for our original hypothesis that the AF CAF framework (mental, physical, social and spiritual fitness) can also be conceptualized as a total measure of Comprehensive Airman Fitness (Total CAF). As a single measure, Total CAF has potential utility for informing AF policy and program activities. AF leadership efforts, and AF 
installation program activities and services, are directed at ensuring that AF members are prepared to carry out the AF mission. Achieving this goal requires promoting and sustaining "a fit, resilient, and ready force" — the foundation of the CAF concept (AFI 90-506, p. 3). Providing a reliable and valid measure of CAF that can be readily obtained, widely understood, inexpensively monitored, and easily communicated across AF leaders, policy makers, and practitioners is critical to achieving and maintaining a mission-ready force. Importantly, the CAF measure provides a ready assessment tool that supports the community practice strategy in the AF (Bowen \& Martin, 2015). A key component of this multifaceted strategy is unit outreach. Both strengths-based and results-focused assessment is a critical aspect of this six-step practice strategy: engagement, assessment, planning, implementation, evaluation and sustainment.

Whether used by unit leaders as a component of their awareness and on-going monitoring of unit members' well-being, or by AF policy makers to address system-wide personnel issues, or by installation practitioners to enhance local human services, the measure described here has great potential utility and warrants further development as an asset for enhancing AF CAF efforts. The fact that this Total CAF measure appears to be stable across so many sub-groupings within the larger AF population adds significantly to its value as an assessment tool. The simplicity of design offers great potential for utilization in a wide array of forms and settings ranging from inclusion in AF-Wide population surveys to adaptation as a stand-alone internetbased app for tablets or cell phones, allowing data to be collected across various assessment strategies. This would include use by individuals for self-assessment purposes, either as part of a practitioner-directed intervention/service, or simply as a self-help tool that might be connected to on-line information and internet-based psycho-educational services that promote behaviors indicative of the core CAF components. The T2 MoodTracker Mobile App is an example of such 
a self-assessment tool, which is available through the National Center for Telehealth \& Technology, Joint Base Lewis-McChord, Washington (www.t2health.org).

Although the current data only allow for the examination of correlational associations among measures, the results of our analyses add to our knowledge and our appreciation of the apparent connection between total fitness and successful performance of important life rolesnotable findings from an intervention research perspective. As stated earlier, the AF has a number of unit and installation-based interventions in place to influence fitness, including mandatory resilience training and education for all active duty Airman and programs like Wingman Day that include various resiliency promotion activities (AFI 90-506, 2014); yet, the AF has not developed a model or methods for a comprehensive assessment of the results from any of these initiatives. In particular, the AF lacks a way to directly connect these various program activities and services with any outcome associated with member performance. The Total CAF measure presented here offers the potential for a "rapid-assessment" metric that can be used to monitor/manage leadership initiatives and installation-based program elements directed to a common performance-based outcome language. This kind of "summary" indicator has the capacity to serve as a dashboard for monitoring, directing, and guiding unit and installation human service efforts - and to recognize quickly when things are going off track. The AF has hired Community Support Coordinators (CSCs) at all AF bases to work with unit leaders to deliver unit-based resilience training and to serve as the Installation Resilience Program Specialist (Bowen \& Martin, 2015). These measures/tools also provide individual human services providers and their customers/clients with a simple, easy to understand, selfassessment tool that can be then further linked to self-help and community resources.

\section{Limitations and Implications for Future Research}


We note a number of limitations associated with our study. Because our data come from non-probability sampling, our results and conclusions may not be generalizable to the full AF population. We would encourage the AF to consider including the 12-item CAF measure on the 2016 iteration of its AF Community Assessment survey, which is administered biennially to a representative sample of active duty members, Guard \& Reserve members, and civilian employees across the AF (AFI 90-501, 15 October 2013).

An important research goal is to obtain data at multiple points in time so that the testretest reliability of $\mathrm{CAF}$ instrument can be determined, as well as to empirically demonstrate the influence of the Total CAF measure on performance outcomes like resiliency across time. There is still a need to examine the model used here for civilian spouses of AF members who are also included in the broad definition of "Airman" in the AF Instruction.

Further examination of criterion-related and construct validity of the CAF instrument is warranted. Specifically, future work should examine the extent to which the CAF instrument correlates (a) with existing fitness measures, such as the Comprehensive Soldier Fitness instrument (i.e., criterion validity) and (b) with other theoretically related constructs, such as personal adaptation, life satisfaction, and deployment readiness (i.e., convergent validity). In particular, in the context of intervention research, it would be important to determine the sensitivity and specificity of the CAF instrument to detecting changes in Airmen participating in resilience training and education. The use of the 11-point scale for evaluating each item allows respondents to report refined shifts in their perceptions.

Some further re-specification of the items used to assess the core dimensions of fitness may also be helpful. For example, the importance of getting sufficient sleep may be a better indicator of "health" than the current use of a "healthy lifestyle" item. Sleep, along with diet and 
exercise seem to intuitively better represent the foundation of physical health behaviors leading to health fitness. Such refinements are the "part and parcel" in the development of measurement instruments. Finally, further iterations of the assessment tool should include a measure to assess the potential for social desirability of response-many of the items on the 12-item CAF measure lend themselves to having respondents answer in a favorable or expected manner. 


\section{References}

Air Force Instruction (AFI) 90-501 (15 October 2013). Community Action Information Board $(C A I B)$ and Integrated Delivery System (IDS). Washington, DC: Department of the Air Force.

Air Force Instruction (AFI) 90-506 (2 April 2014). Comprehensive Airman Fitness (CAF). Washington, DC: Department of the Air Force.

Bowen, G. L., Jensen, T. M., \& Martin, J. A. (in review). Confirmatory factor analysis of a measure of comprehensive airman fitness.

Bowen, G.L., \& Martin, J. A. (2011a). The resiliency model of role performance of service members, veterans, and their families. Journal of Human Behavior in the Social Environment, $21,162-178$.

Bowen, G. L., \& Martin, J. A. (2011b). The Support \& Resiliency Inventory (Version 3, SRI-M). Chapel Hill, NC: Bowen \& Colleagues. doi: 10.13140/RG.2.1.1943.4402

Bowen, G. L., \& Martin, J. A. (2013). Support and Resiliency Inventory (SRI-M): Six-month utilization report (January-June 2013). Charlotte, NC: Flying Bridge Technologies. doi: $10.13140 / 2.1 .1536 .0327$

Bowen, G. L., \& Martin, J. A (2015). Building community capacity in the U.S. Air Force: Promoting a community practice strategy. In K. Corcoran \& A. R. Roberts (Eds.), Social workers' desk reference ( $3^{\text {rd }}$ ed., pp. 935-940). New York, NY: Oxford University Press.

Bowen, N., \& Guo, S. (2012). Structural equation modeling. New York: Oxford University Press.

Bowen, N., \& Masa, R. (2015). Conducting measurement invariance tests with ordinal data: A guide for social work researchers. Journal of the Society for Social Work and Research, 6(2), 229-249. 
Browne, M. W., \& Cudeck, R. (1993). Alternative ways of assessing model fit. In K. A. Bollen \& J. S. Long (Eds.), Testing structural equation models (pp. 136-162). Newbury Park, CA: Sage.

Byrne, B., Shavelson, R., \& Muthen, B. (1989). Testing equivalence of factor covariance and mean structures: The issue of partial measurement invariance. Psychological Bulletin, 105(3), 456-466.

Cantril, H. (1965). The pattern of human concerns. New Brunswick, NJ: Rutgers University Press.

Chairman of the Joint Chiefs of Staff Instruction (CJCSI) 3405.01 (1 September 2011), Chairman's total force fitness framework.

Cheung, G. W., \& Rensvold, R. B. (2002). Evaluating goodness-of-fit indexes for testing measurement invariance. Structural Equation Modeling: A Multidisciplinary Journal, 9(2), 233-255.

Chen, F. F., Sousa, K. H., \& West, S. G. (2005). Teacher's corner: Testing measurement invariance of second-order factor models. Structural Equation Modeling: A Multidisciplinary Journal, 12(3), 471-492.

Curran, P. J., West, S. G., \& Finch, J. F. (1996). The robustness of test statistics to nonnormality and specification error in confirmatory factor analysis. Psychological Methods, 1(1), 16.

Department of the Air Force, Office of the Chief of Staff (12 January 2012a). Resiliency stand down. Washington, DC: Author.

Department of the Air Force, Office of the Chief of Staff (12 January 2012b). Talking points for individual and group discussion during resiliency stand down. Washington, DC: Author. 
DeVellis, R. (2012). Scale development: Theory and applications (3rd ed.). Thousand Oaks, CA: Sage.

Dimitrov, D. (2010). Testing for factorial invariance in the context of construct validation. Measurement and Evaluation in Counseling and Development, 43(2), 121-149.

Gonzalez, G. C., Singh, R., Schell, T. L., \& Weinick, R. M. (2014). An evaluation of the implementation and perceived utility of the airman resilience training program. Santa Monica, CA: RAND Corporation.

Hu, L. T., \& Bentler, P. M. (1999). Cutoff criteria for fit indexes in covariance structure analysis. Conventional criteria versus new alternatives. Structural Equation Modeling: A Multidisciplinary Journal, 6(1), 1-55.

Kline, R. (2011). Principles and practice of structural equation modeling (3rd ed.). New York: Guilford.

MacCallum, R. C., Browne, M. W., \& Sugawara, H. M. (1996). Power analysis and determination of sample size for covariance structure modeling. Psychological Methods, 1(2), 130-149.

Muthén, L.K., \& Muthén, B.O. (2012). Mplus user's guide, 7th edition. Los Angeles, CA: Muthén \& Muthén.

Peterson, C., Park, N., \& Castro, C. A. (2011). Assessment for the US Army Comprehensive Soldier Fitness program: The Global Assessment Tool. American Psychologist, 66(1), 10-18. StataCorp (2013). Stata statistical software: Release 13. College Station, TX: StataCorp LP. Tvaryanas, A. P., Brown, L., \& Miller, N. L. (2009). Managing the human weapon system: A vision for an Air Force human-performance doctrine. Air \& Space Power Journal, XXIII(2), 34-41. 
Wright, K. M., Riviere, L. A., Merrill, J. C., \& Cabrera, O. A. (2013). Resilience in military families: A review of programs and empirical evidence. In R. R. Sinclair \& T. W. Britt (Eds.), Building psychological resilience in military personnel: Theory and practice (pp. 167-191. Washington, DC: American Psychological Association. 
Table 1. USAF Definitions of Four Fitness Domains

\begin{tabular}{ll} 
Fitness Domain & Definition \\
\hline Mental Fitness & The ability to effectively cope with unique mental stressors and challenges. \\
Physical Fitness & The ability to adopt and sustain healthy behaviors needed to enhance health and well-being \\
Social Fitness & The ability to engage in healthy social networks that promote overall well-being and optimal performance. \\
Spiritual Fitness & The ability to adhere to beliefs, principles, or values needed to persevere and prevail in accomplishing missions. \\
&
\end{tabular}

Source: AFI90-506, 2 April 2014, Comprehensive Airman Fitness, pp. 15-16. 
Table 2. Variable and Sample Description for the Full Sample $(N=10,846)$

\begin{tabular}{|c|c|c|c|c|c|c|c|c|}
\hline Variable & $\mathrm{N}$ & mean & SD & Skewness & Kurtosis & Min & Max & Missing Values \\
\hline \multicolumn{9}{|l|}{ Resiliency Variables } \\
\hline R1 & 10,136 & 8.39 & 1.78 & -1.65 & 6.75 & 0 & 10 & $6.5 \%$ \\
\hline R2 & 10,653 & 8.84 & 1.45 & -1.95 & 8.66 & 0 & 10 & $1.8 \%$ \\
\hline R3 & 10,612 & 8.42 & 1.76 & -1.56 & 6.14 & 0 & 10 & $2.2 \%$ \\
\hline \multicolumn{9}{|l|}{ Fitness Variables } \\
\hline \multicolumn{9}{|l|}{ Mental Fitness } \\
\hline MF1 & 10,671 & 7.22 & 2.60 & -0.89 & 3.07 & 0 & 10 & $1.6 \%$ \\
\hline MF2 & 10,699 & 8.16 & 2.07 & -1.39 & 4.86 & 0 & 10 & $1.4 \%$ \\
\hline MF3 & 10,699 & 7.84 & 2.23 & -1.24 & 4.21 & 0 & 10 & $1.4 \%$ \\
\hline \multicolumn{9}{|l|}{ Physical Fitness } \\
\hline PF1 & 10,707 & 7.13 & 1.95 & -0.65 & 3.52 & 0 & 10 & $1.3 \%$ \\
\hline PF2 & 10,688 & 7.48 & 2.49 & -1.01 & 3.41 & 0 & 10 & $1.5 \%$ \\
\hline PF3 & 10,704 & 7.41 & 2.01 & -0.80 & 3.57 & 0 & 10 & $1.3 \%$ \\
\hline \multicolumn{9}{|l|}{ Social Fitness } \\
\hline SCF1 & 10,566 & 8.09 & 2.62 & -1.44 & 4.20 & 0 & 10 & $2.6 \%$ \\
\hline SCF2 & 10,543 & 7.66 & 2.59 & -1.09 & 3.43 & 0 & 10 & $2.8 \%$ \\
\hline SCF3 & 10,563 & 6.97 & 2.85 & -0.74 & 2.58 & 0 & 10 & $2.6 \%$ \\
\hline \multicolumn{9}{|l|}{ Spritual Fitness } \\
\hline SPF1 & 10,572 & 8.76 & 1.81 & -2.04 & 8.02 & 0 & 10 & $2.5 \%$ \\
\hline SPF2 & 10,561 & 8.66 & 1.82 & -1.96 & 7.76 & 0 & 10 & $2.6 \%$ \\
\hline SPF3 & 10,470 & 8.36 & 2.18 & -1.75 & 6.09 & 0 & 10 & $3.5 \%$ \\
\hline \multicolumn{9}{|l|}{ Grouping Variable } \\
\hline Service Component & & & & & & & & $0.00 \%$ \\
\hline Active duty & 8,671 & $80 \%$ & & & & & & \\
\hline Reserve & 417 & $4 \%$ & & & & & & \\
\hline Civilian & 1,758 & $16 \%$ & & & & & & \\
\hline \multicolumn{9}{|l|}{ Other Characteristics } \\
\hline Gender $(1=$ male $)$ & 8,086 & $75 \%$ & & & & & & $0.37 \%$ \\
\hline Marital status ( 1 = married) & 6,729 & $62 \%$ & & & & & & $0.00 \%$ \\
\hline Age & & & & & & & & $0.45 \%$ \\
\hline Under 26 & 3,844 & $35 \%$ & & & & & & \\
\hline $26-35$ years & 2,859 & $30 \%$ & & & & & & \\
\hline 36 and older & 4,094 & $26 \%$ & & & & & & \\
\hline Parent or Stepparent ( $1=$ yes) & 6,104 & $56 \%$ & & & & & & $0.00 \%$ \\
\hline
\end{tabular}


Table 3. Observed Indicators for Each First-Order Latent Construct

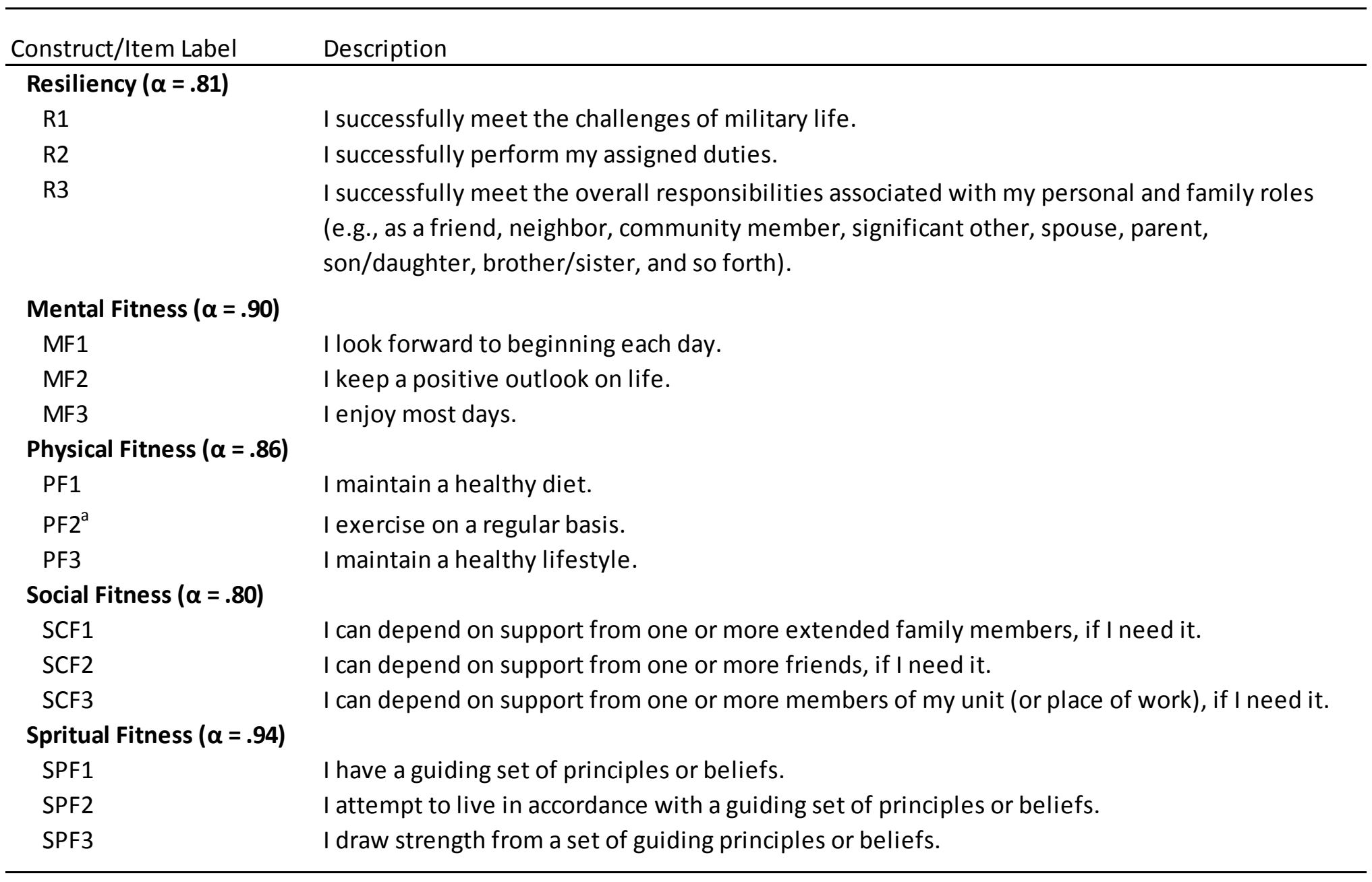

Note: All dimensions range from 0 (Not At All) to 10 (Completely). ${ }^{a}$ The Center for Disease Control defines minimum regular exercise as $\mathbf{1 5 0}$ minutes per week of moderate intensity aerobic activity, as well as muscle strengthening activities two or more times per week. Survey respondents were issued this definition. 
Table 4. Correlation Matrix of Observed Indicators

\begin{tabular}{|c|c|c|c|c|c|c|c|c|c|c|c|c|c|c|c|}
\hline & 1 & 2 & 3 & 4 & 5 & 6 & 7 & 8 & 9 & 10 & 11 & 12 & 13 & 14 & 15 \\
\hline \multicolumn{16}{|l|}{ Resiliency } \\
\hline \multicolumn{16}{|l|}{$1 \mathrm{R} 1$} \\
\hline $2 \mathrm{R} 2$ & $0.69 *$ & & & & & & & & & & & & & & \\
\hline 3 R3 & $0.54 *$ & $0.56 *$ & & & & & & & & & & & & & \\
\hline \multicolumn{16}{|c|}{ Mental Fitness } \\
\hline 4 MF1 & $0.46 *$ & $0.41 *$ & $0.46 *$ & & & & & & & & & & & & \\
\hline 5 MF2 & $0.49 *$ & $0.43 *$ & $0.51 *$ & $0.72 *$ & & & & & & & & & & & \\
\hline $6 \mathrm{MF} 3$ & $0.49 *$ & $0.44 *$ & $0.50 *$ & $0.79 *$ & $0.79 *$ & & & & & & & & & & \\
\hline \multicolumn{16}{|c|}{ Physical Fitness } \\
\hline 7 PF1 & $0.35 *$ & $0.29 *$ & $0.32 *$ & $0.39 *$ & $0.39 *$ & $0.36 *$ & & & & & & & & & \\
\hline 8 PF2 & $0.30 *$ & $0.23 *$ & $0.25 *$ & $0.29 *$ & $0.30 *$ & $0.28 *$ & $0.58 *$ & & & & & & & & \\
\hline 9 PF3 & $0.38 *$ & $0.32 *$ & $0.37^{*}$ & $0.41 *$ & $0.43 *$ & $0.40 *$ & $0.79 *$ & $0.72 *$ & & & & & & & \\
\hline \multicolumn{16}{|c|}{ Social Fitness } \\
\hline 10 SCF1 & $0.27 *$ & $0.22 *$ & $0.35 *$ & $0.34 *$ & $0.37 *$ & $0.36 *$ & $0.24 *$ & $0.18 *$ & $0.25 *$ & & & & & & \\
\hline 11 SCF2 & $0.33 *$ & $0.28 *$ & $0.39 *$ & $0.39 *$ & $0.43 *$ & $0.43 *$ & $0.28 *$ & $0.24 *$ & $0.30 *$ & $0.57 *$ & & & & & \\
\hline 12 SCF3 & $0.37 *$ & $0.28 *$ & $0.32 *$ & $0.42 *$ & $0.42 *$ & $0.45 *$ & $0.28 *$ & $0.24 *$ & $0.28 *$ & $0.47 *$ & $0.66 *$ & & & & \\
\hline \multicolumn{16}{|c|}{ Spiritual Fitness } \\
\hline 13 SPF1 & $0.38 *$ & $0.35 *$ & $0.36 *$ & $0.39 *$ & $0.42 *$ & $0.38 *$ & $0.29 *$ & $0.19 *$ & $0.31 *$ & $0.25 *$ & $0.29 *$ & $0.27 *$ & & & \\
\hline 14 SPF2 & $0.38 *$ & $0.36 *$ & $0.38 *$ & $0.40 *$ & $0.44 *$ & $0.40 *$ & $0.30 *$ & $0.19 *$ & $0.32 *$ & $0.25 *$ & $0.28 *$ & $0.27 *$ & $0.90 *$ & & \\
\hline 15 SFP3 & $0.36 *$ & $0.34 *$ & $0.38 *$ & $0.43 *$ & $0.46 *$ & $0.42 *$ & $0.29 *$ & $0.19 *$ & $0.32 *$ & $0.26 *$ & $0.30 *$ & $0.28 *$ & $0.81 *$ & $0.83 *$ & \\
\hline
\end{tabular}

Note: ${ }^{*} p<.05$. Analysis included non-missing data ( $N=9,876$ to 10,707$)$. All variance inflaction factor scores across items were below 6 in the context of a supplemental analysis, indicating no issue with multicollinearity. 
Table 5. Baseline Measurement Model, Measurement/Structural Invariance Tests by Service Component, and Model Fit Indices $(N=10,805)$

\begin{tabular}{|c|c|c|c|c|c|c|c|c|c|c|c|}
\hline Model & $\mathrm{N}$ & Parameters & Chi-square & $\mathrm{df}$ & $\mathrm{p}$-value & RMSEA & $\begin{array}{l}\text { Upper- } \\
\text { bound }\end{array}$ & TLI & $\mathrm{CFI}$ & $\triangle \mathrm{CFI}$ & Comparison \\
\hline \multicolumn{12}{|l|}{ Baseline Measurement Model - All Constructs } \\
\hline Model 1: Baseline Model (full sample) ${ }^{a}$ & 10,805 & 50 & 1094.918 & 50 & $<.001$ & 0.044 & 0.046 & 0.985 & 0.988 & & \\
\hline \multicolumn{12}{|l|}{ Measurement Invariance Tests: Service Component (3 Groups) b $^{b}$} \\
\hline Model 2: Configural invariance & 10,805 & 150 & 2572.840 & 255 & $<.001$ & 0.050 & 0.052 & 0.974 & 0.979 & -0.009 & Model 1 \\
\hline Model 3: First-order metric invariance & 10,805 & 120 & 3082.091 & 285 & $<.001$ & 0.052 & 0.054 & 0.972 & 0.974 & -0.005 & Model 2 \\
\hline Model 4: Second-order metric invariance & 10,805 & 112 & 3170.399 & 293 & $<.001$ & 0.052 & 0.054 & 0.972 & 0.974 & 0.000 & Model 3 \\
\hline Model 5: Scalar invariance & 10,805 & 82 & 4850.004 & 323 & $<.001$ & 0.062 & 0.064 & 0.960 & 0.959 & -0.015 & Model 4 \\
\hline Model 6: Partial scalar invariance (14 out of 15 parameters, 93\%) & 10,805 & 84 & 4186.046 & 321 & $<.001$ & 0.058 & 0.059 & 0.965 & 0.965 & -0.009 & Model 4 \\
\hline \multicolumn{12}{|l|}{ Structural Invariance Tests: Service Component ( 3 Groups) ${ }^{b}$} \\
\hline Model 7: Structural model & 10,805 & 84 & 4165.619 & 321 & $<.001$ & 0.058 & 0.059 & 0.965 & 0.965 & 0.000 & Model 6 \\
\hline Model 8: Structural invariance & 10,805 & 82 & 4187.358 & 323 & $<.001$ & 0.058 & 0.059 & 0.966 & 0.965 & 0.000 & Model 7 \\
\hline
\end{tabular}

Note: ${ }^{\mathrm{a}} 41$ cases are omitted due to missing values on all variables. ${ }^{\mathrm{b}}$ Component subgroups: Active Duty $(\mathrm{N}=8,633)$, AF Reserve $(\mathrm{N}=417), \mathrm{AF}$ Cilivian ( $\left.\mathrm{N}=1,755\right)$. Bold $\Delta \mathrm{CFI}$ indicates a significant diminishment of model fit from the previous model. Invariance tests were conducted as outlined in Chen, Sousa, and West (2005). 
Figure 1. Hypothesized Model

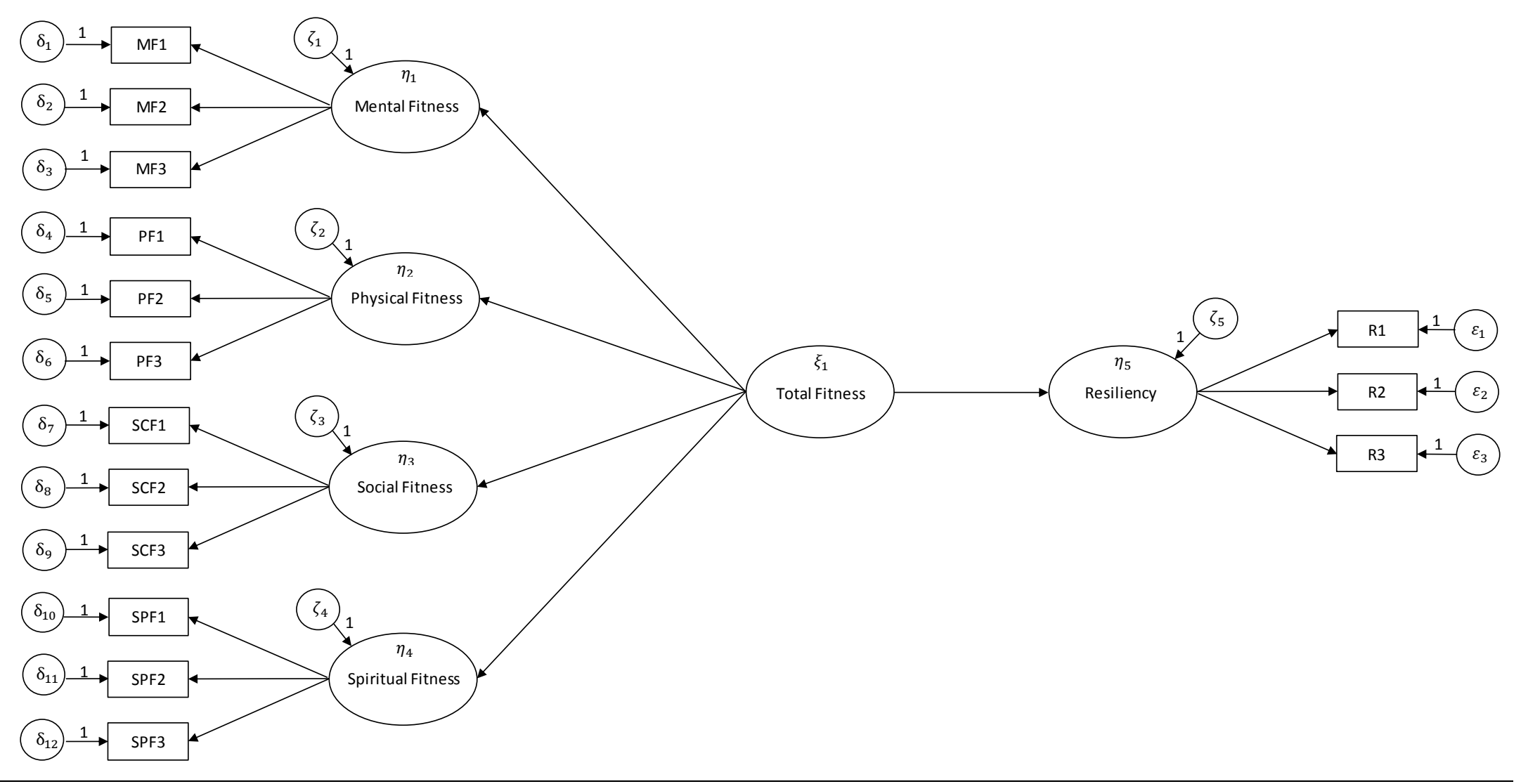

Note: For metric calibration, the variance/error variance of first- and second-order factors are fixed to 1. 
Figure 2. Final Model With Full Sample and Standardized Estimated Parameters $(N=10,805)$

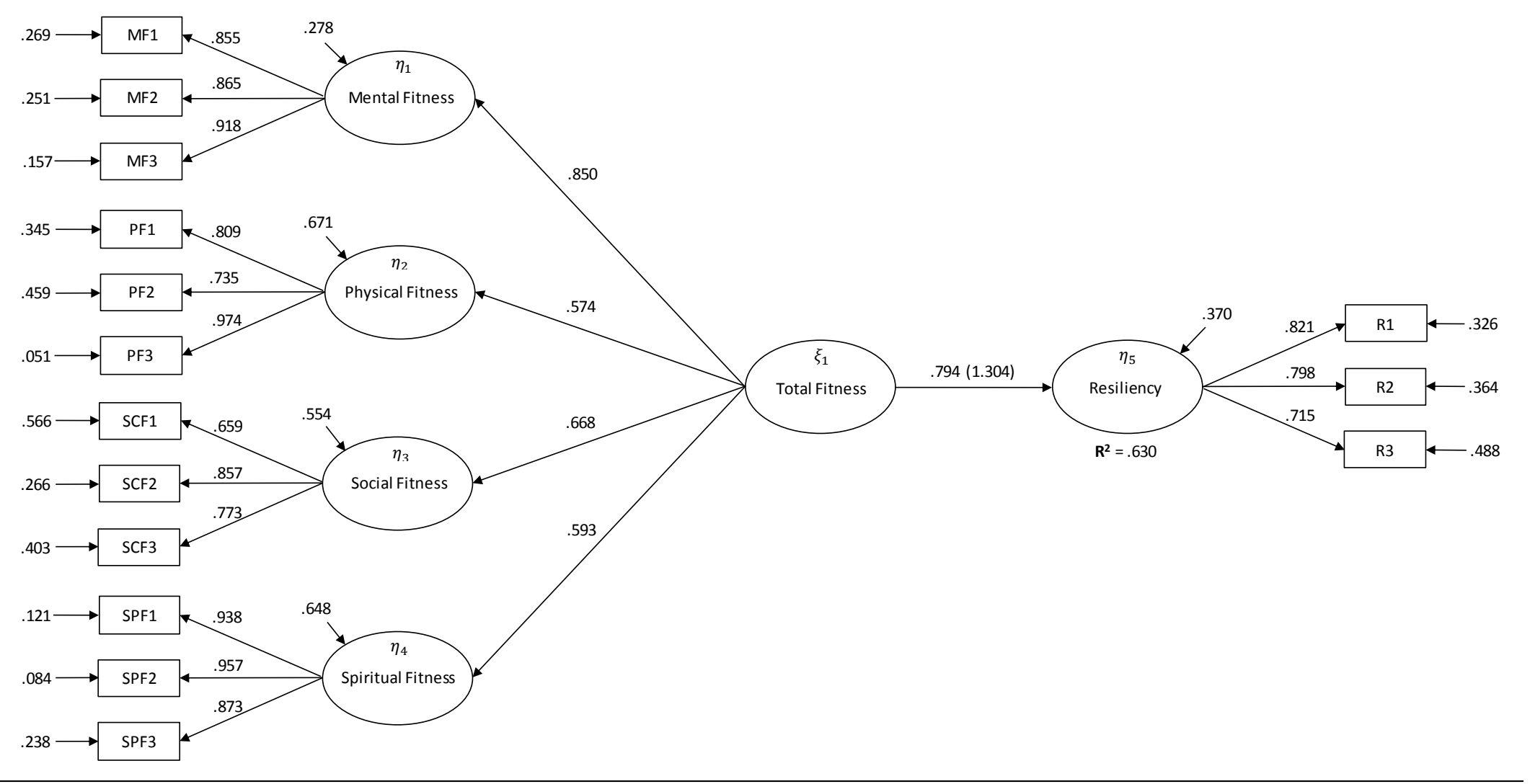

Note: Model fit indices: $\mathrm{X2}(85)=2328.756, \mathrm{p}<.001, \mathrm{RMSEA}=.049[90 \% \mathrm{Cl}: .048-.051], \mathrm{TLI}=.974, \mathrm{CFI}=.979$. Maximum Likelihood estimator was used for the analysis. All estimated parameters are significant at the $\mathrm{p}<.001$ level. Forty-one cases were omitted from the analyis because they were missing values on all observed indicators. Value in parentheses indicates unstandardized path coefficient. 